\title{
Assessment of Radioactive Concentrations in the Egyptian Natural Gas Grid and Their Relevant Impacts
}

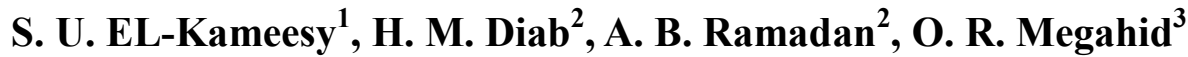 \\ ${ }^{1}$ Department of Physics, Faculty of Science, Ain-Shams University, Cairo, Egypt \\ ${ }^{2}$ Radiation Nuclear and Radiological Authority, Cairo, Egypt \\ ${ }^{3}$ Department of Health and Safety, Midor, Ministry of Petroleum, Cairo, Egypt
}

Email address:

samirkhamisy@yahoo.com (S. U. EL-Kameesy)

\section{To cite this article:}

S. U. EL-Kameesy, H. M. Diab, A. B. Ramadan, O. R. Megahid. Assessment of Radioactive Concentrations in the Egyptian Natural Gas Grid and Their Relevant Impacts. American Journal of Physics and Applications. Vol. 4, No. 6, 2016, pp. 152-157. doi: 10.11648/j.ajpa.20160406.13

Received: October 31, 2016; Accepted: November 17, 2016; Published: December 29, 2016

\begin{abstract}
The radioactivity concentrations of ${ }^{226} \mathrm{Ra},{ }^{232} \mathrm{Th}$ and ${ }^{40} \mathrm{~K}$ in thirty samples representing the technically Naturally Occurring Radioactive Materials (NORM) in the Egyptian natural gas were investigated. The investigations were performed using a gamma ray spectroscopy technique. The obtained data were used to establish a data base for NORM concentrations during the different processing stages of natural gas and to estimate the associated radiation health hazard impacts. Great concern has been devoted to determine the specific activity of ${ }^{210} \mathrm{~Pb}$ as it represents all daughters originating from ${ }^{222} \mathrm{Rn}$ that have relatively short half-lives. The samples were collected from the gas pipeline grid covering different areas in Egypt. Fifteen samples were taken from the gas pipelines, whereas the remaining samples were taken from the upstream facilities before pumping into the grid. The average activity concentrations of ${ }^{226} \mathrm{Ra},{ }^{232} \mathrm{Th}$ and ${ }^{40} \mathrm{k}$ were found to be $16.2 \pm 1.5,10.50 \pm$ 0.9 and $98.46 \pm 6.03 \mathrm{~Bq} / \mathrm{kg}$ for filter samples respectively. The corresponding average values for scale samples were $37.28 \pm$ $3.1,45.7 \pm 2.6$ and $621.79 \pm 9.2 \mathrm{~Bq} / \mathrm{kg}$. The sludge samples gave average values of $14.97 \pm 1.94,9.99 \pm 1.48$ and $112.82 \pm$ 5.82 respectively. These values are below the recommended international limits. In contrary, the average values of activity concentrations of waste water were found to be $4.895 \pm 0.51,2.241 \pm 0.3$ and $31.852 \pm 2.31 \mathrm{~Bq} / \mathrm{kg}$ respectively. The obtained results indicate that ${ }^{226} \mathrm{Ra}$ content is higher than the recommended values for domestic or drinking water. Additionally, high values of the specific activity of ${ }^{210} \mathrm{~Pb}$ were found in both deposits and filter samples.
\end{abstract}

Keywords: NORM, Egyptian Natural Gas, Scales, Sludge, Waste Water, Absorbed Dose Rate, Radium Equivalent Activity, Gamma Index

\section{Introduction}

Earth's crust contains Naturally Occurring Radioactive Materials (NORM) at measurable concentrations. The sources of most NORM are ${ }^{226} \mathrm{Ra},{ }^{232} \mathrm{Th}$ and ${ }^{40} \mathrm{~K}$. These isotopes are naturally present in subsurface formations from which oil and natural gas are produced. Radium-226 and radium-228 are the main radionuclides of concern in NORM wastes which are produced from the decay series of ${ }^{238} \mathrm{U}$ and ${ }^{232} \mathrm{Th}$. Other radionuclides are those produced from the decay of ${ }^{228} \mathrm{Ra}$ and ${ }^{226} \mathrm{Ra}$. radioactive isotopes such as uranium-238, radium-228and radon-222 are dissolved in very low concentrations during normal reactions between water and earth constituents such as rock. The water existed with underground oil and natural gas has usually considerable amounts of radionuclides formed during the prolonged periods of water/rock contact [1]. The isotope of radium which is slightly soluble can be mobilized in the liquid phases of formation and transported to the surface in the produced water stream. Hence, dissolved radium does exist in produced water or precipitated in scales, sludge and processing equipment. Radium concentrations are generally reported as a picocuries / gram $(\mathrm{pCi} / \mathrm{L})$ of water or air. A picocurie 
equals 2.22 disintegrations- per- minute (dpm). The contaminated water, scales, sludge and equipment cause exposure problems when the equipment is taken off-line for maintenance, repair or replacement. Moreover, the produced natural gas and its processing equipment also may be contaminated with a thin film of lead-210 which is deposited onto the interior surfaces [2 - 5].

Although the presence of NORM in oil and natural gas are well known for more than 8 decades, however the health risks were not considered before the mid of 1980s when the industry and regulators realized that NORM concentration is more than it was expected. Therefore, the radiation dose level could be more than that from natural background. This means that workers in the field of oil and natural gas production and the general public users may be exposed to radiation emitted from NORM contaminated equipment from streams. This means that the magnitude of radiation risk requires an assessment of the exposure dose during stages of production, management and uses [6-9].

It is worth to mention that, although NORM concentration in oil and natural gas is usually low, the level of concentration may become enhanced during the process of extraction and production. These include water, scales, sludge and begging debris [10], [11]. Accordingly, uncontrolled work activities involving NORM can lead to undesirable exposure to radiation hazard and therefore cause a risk to human health. This risk can be reduced by the adaptation of appropriate controls to the presence of NORM. In addition, a best working practice at NORM areas has to be considered to protect the workers in these areas from the hazards of ionizing radiations. This is usually achieved by controlling the exposure and by the use of adequate dose measurements. However, the environmental impact and subsequently the radiation effect on the public are mostly reduced by controlled disposal of NORM/waste and by the adaptation of emission controls [12].

Accordingly, the aim of the present work is to study the radioactivity for different trajectory zones of the Egyptian Natural Gas Grid to assess the possible associated health hazards and establishing a radiological baseline for any corresponding future studies.

\section{Experimental Technique and Measurements}

Fifteen sludge samples were collected during the cleaning and maintenance processes of the pipelines of national natural gas grid. Other 15 samples are taken from upstream plant facilities. These include samples of scales, filters and waste water. A photograph of a sludge sample taken during the cleaning of the interior surface of pipeline and a photograph of scales taken from a tank upstream plant facilities are shown in fig. 1 and fig. 2 respectively.

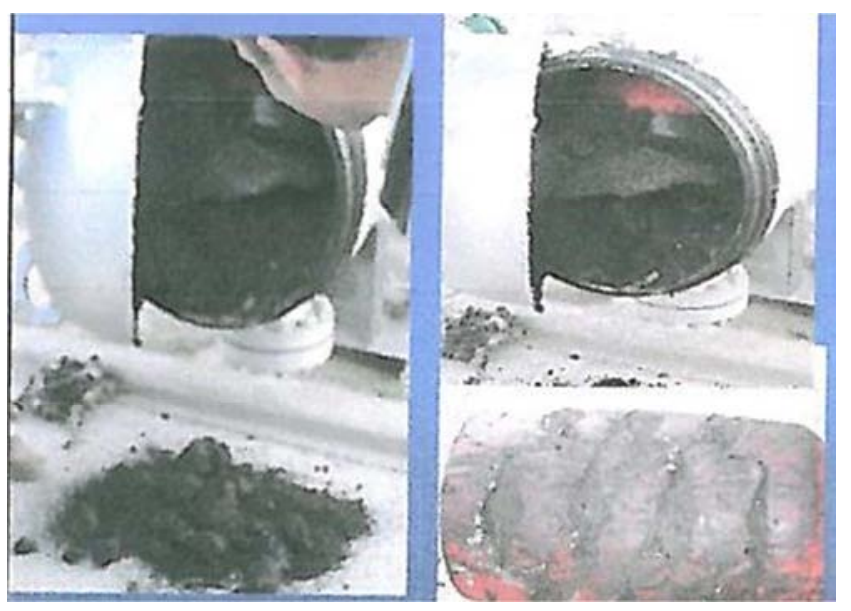

Fig. 1. An example of the sludge sample.

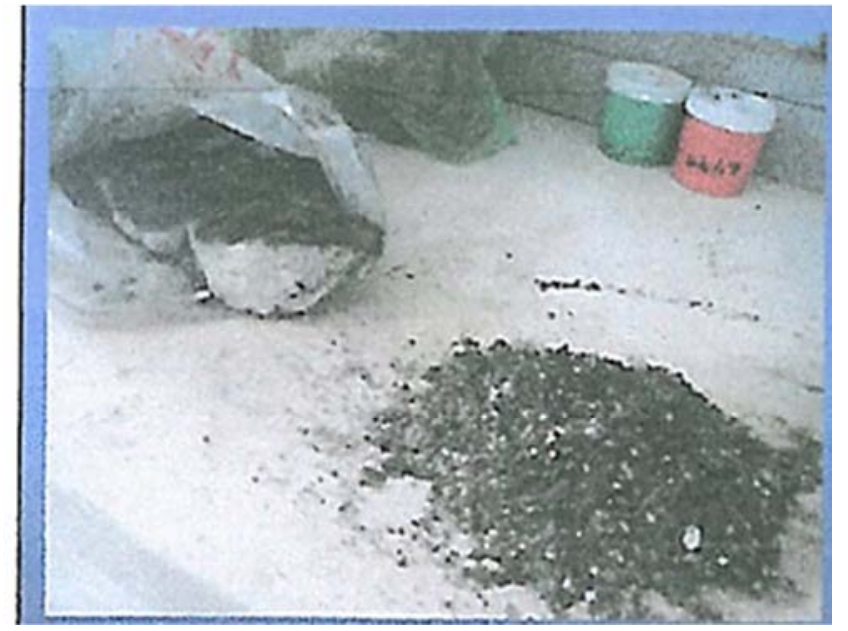

Fig. 2. An example of the scales sample.

The sediment samples (sludge, scales) were dried in an oven at $105^{\circ} \mathrm{C}$ for $24 \mathrm{~h}$, crushed and sieved by $1 \mathrm{~mm}$ sieve to remove mechanical waste. Then, the samples were weighted and packed in cans $\left(100 \mathrm{~cm}^{3}\right)$ for six weeks to reach secular equilibrium where the rate of decay of the progeny is equal to that of the parent. The water samples were acidified with $20 \mathrm{~mm}$ of hydrochloride at the rate of $20 \mathrm{ml}$ as soon as possible after sampling to prevent adsorption of radio-nuclides in the bottles.

In order to analyse the water samples five litres of it were evaporated to one litre, and put into $100 \mathrm{ml}$ marinelli beakers. These marinelli beakers were previously washed, rinsed with a dilute sulfuric acid and dried to avoid any contamination. Hereafter, they firmly sealed for at least four weeks to ensure that no loss of radon occurs there by ensuring a state of secular equilibrium to be reached between radium isotopes and their respective daughters.

\subsection{Radioactivity Measurements}

A closed end-coaxial Canberra N-type HPGe detector of vertical configuration (model GC 5019); with $40 \%$ relative efficiency and $2.0 \mathrm{keV}$ energy resolution at $1.33 \mathrm{MeV}$ photons was used to detect the gamma ray single spectrum. To reduce gamma-ray background, a cylindrical lead shield 
of thickness $5 \mathrm{~cm}$ was used. The lead shield contained an inner concentric copper cylinder ( $1 \mathrm{~mm}$ thick) to prevent $\mathrm{x}$ ray and Bremsstrahlung radiation production. The spectra were analysed by means of maestro program. The energy and efficiency calibration of the spectrometer were performed using an analogous calibrated can $\left(100 \mathrm{~cm}^{3}\right)$ which contains well known standard sources $\left({ }^{22} \mathrm{Na},{ }^{60} \mathrm{Co}\right.$ and $\left.{ }^{226} \mathrm{Ra}\right)$ along with a standard solution of $\mathrm{HCl}$. Quality control and quality assurance of the measurements using international atomic energy agency (IAEA) reference materials (soil 6, IAEA362) have been applied.

The specific activity of ${ }^{226} \mathrm{Ra}$ was calculated on the basis of the energy transitions of $295.1 \mathrm{keV}(19.2 \%)$ and 352.0 $\operatorname{keV}(37.1 \%)$ of ${ }^{214} \mathrm{~Pb}, 609.3 \mathrm{keV}(46.1 \%), 1120 \mathrm{keV}(15.1 \%)$ and $1764.5 \mathrm{keV}(15.9 \%)$ of ${ }^{214} \mathrm{Bi}$. The corresponding specific activity of ${ }^{232} \mathrm{Th}$ was calculated making use of the energy transition $338.4 \mathrm{keV}(12.4 \%)$ and $911.2 \mathrm{keV}(25.9 \%)$ of ${ }^{228} \mathrm{Ac}, 583.19 \mathrm{keV}(40.4 \%)$ and $2614 \mathrm{keV}(35.6 \%)$ of ${ }^{208} \mathrm{Tl}$ and $238.63 \mathrm{keV}(43.3 \%)$ of ${ }^{212} \mathrm{~Pb}$.

The activity concentrations of ${ }^{40} \mathrm{~K}$ was obtained from the $1460.7 \mathrm{keV}$ (10.67\%) gamma line. The activity concentration is based on the following equation [13];

$$
\mathrm{A}=\mathrm{Np} /(\lambda \times \mathbf{\eta} \times \mathrm{m})
$$

where $N_{p}$ is the net count rate, $\lambda$ is the abundance of the gamma line in radionuclide, $\boldsymbol{\eta}$ is the detector efficiency of the specific $\mathrm{y}$-ray and $\mathrm{m}$ is the mass of the sample $(\mathrm{kg})$.

The combined uncertainty of activity can be calculated by the following equation;

$$
\frac{U^{2}(\mathrm{~A})}{A^{2}}=\frac{U^{2}(N p)}{N^{2}}+\frac{U^{2}(\eta)}{\eta^{2}}+\frac{\mathrm{U}^{2}(\lambda)}{\lambda^{2}}+\frac{U^{2}(m)}{m^{2}}
$$

The reproducibility of the results and the stability of the counting technique were checked by conducting triplicate analysis on the collected samples.

\subsection{Gamma-Ray Radiation Hazard Indices}

As the activity of ${ }^{226} \mathrm{Ra}$ or any of its daughters represents about $98.5 \%$ of that of ${ }^{238} \mathrm{U}$. Therefore, the contribution from ${ }^{238} \mathrm{U}$ could be replaced with any of them. The gamma radiation hazards due to the specific radionuclides were assessed by four different indices; the radium equivalent $\left(R a_{\text {eq }}\right)$, the absorbed dose rate (D), the annual effective dose rate (AEDE) and gamma index. $\mathrm{Ra}_{\mathrm{eq}}$ can be calculated according to the following equation [14];

$$
\mathrm{Ra}_{\mathrm{eq}}=\boldsymbol{A}_{\boldsymbol{R} \boldsymbol{a}}+1.43 \boldsymbol{A}_{\boldsymbol{T h}}+0.077 \boldsymbol{A}_{\boldsymbol{K}}
$$

Where, $A_{R a}, A_{T h}$ and $A_{K}$ are the activity concentrations of ${ }^{226} \mathrm{Ra},{ }^{232} \mathrm{Th}$ and ${ }^{40} \mathrm{~K}$, in $\mathrm{Bq} / \mathrm{kg}$ respectively. The $\mathrm{Ra}_{\mathrm{eq}}$ is related to the external gamma dose and internal dose due to radon and its daughters. The maximum value of $\mathrm{Ra}_{\mathrm{eq}}$ must be less than $370 \mathrm{~Bq} / \mathrm{kg}$.

Other hazard parameter is the representative level index $\mathrm{I}_{\gamma \mathrm{r}}$ was calculated using the formula [14];

$$
\mathrm{I}_{\gamma \mathrm{r}}=\frac{\boldsymbol{A}_{\mathrm{Ra}}}{150}+\frac{\boldsymbol{A}_{\mathrm{Th}}}{100}+\frac{\boldsymbol{A}_{\mathrm{K}}}{1500}
$$

The gamma index $\left(\mathrm{I}_{\gamma \mathrm{r}}\right)$ is in the permissible range as long as it is less than unity.

The absorbed dose rate (D), (Gy/h) was calculated using the following equation [15];

$$
\mathrm{D}=0.462 \mathrm{~A}_{\mathrm{Ra}}+0.604 \mathrm{~A}_{\mathrm{Th}}+0.0417 \mathrm{~A}_{\mathrm{K}}
$$

The annual effective dose equivalent has been calculated using the following equation [15];

$\mathrm{AEDE}=$ Dose Rate $\left(\mathrm{nGyh}^{-1}\right) \times 8760 \mathrm{~h} \times 0.7 \mathrm{~Sv} \mathrm{~Gy}^{-1} \times 0.2 \times 10^{-6}(6)$

Where the $0.7 \mathrm{~Sv} / \mathrm{Gy}$ and 0.2 constants are the conversion factors from absorbed dose in air to effective dose and the outdoor occupancy factor respectively [16].

\section{Results and Discussion}

As shown in table (1), the average activity concentrations of ${ }^{226} \mathrm{Ra},{ }^{232} \mathrm{Th}$ and ${ }^{40} \mathrm{k}$ were found to be $16.206 \pm 1.5,10.506$ \pm 0.9 and $98.46 \pm 6.03 \mathrm{~Bq} / \mathrm{kg}$ for filter samples respectively. For scales samples the corresponding average values are $37.28 \pm 3.01,45.7 \pm 2.6$ and $621.79 \pm 9.5 \mathrm{~Bq} / \mathrm{kg}$. Also, the corresponding average values for sludge samples are $14.97 \pm$ $1.94,9.99 \pm 1.48$ and $112.82 \pm 5.82 \mathrm{~Bq} / \mathrm{kg}$ respectively. Furthermore, the corresponding average activity concentrations of the collected water samples are $4.895 \pm$ $0.51,2.241 \pm 0.33$ and $31.852 \pm 2.31 \mathrm{~Bq} / \mathrm{kg}$ respectively.

The obtained results showed that the activity concentration for ${ }^{226} \mathrm{Ra}$ in the investigated water samples is at least five times higher than the max concentration for ${ }^{226} \mathrm{Ra}(0.6 \mathrm{~Bq} / \mathrm{kg})$ HECE, 1995) [18] or in other words it is higher than the safety value $(1 \mathrm{~Bq} / \mathrm{kg})$ recommended for ${ }^{226} \mathrm{Ra}$ in water (Surbeck, 1995) [17] and the U. S. EPA maximum contaminant level for drinking water $(5 \mathrm{pCi} / 1=0.185 \mathrm{~Bq} / \mathrm{L})$ for total dissolved radium [20], [21]. Some previous works [8] have considered that production water with concentrations below $10 \mathrm{~Bq} / \mathrm{l}\left({ }^{226} \mathrm{Ra}\right)$ and / or $10 \mathrm{~Bq} / \mathrm{l}\left({ }^{210} \mathrm{~Pb}\right)$ may be treated as exempt. Also, from table 1 it is shown that the values of the specific activities of ${ }^{210} \mathrm{~Pb}$ for different samples are high in particular in the gas filter samples lying in the range from 250 to $1664 \mathrm{~Bq} / \mathrm{kg}$ with an average value $260 \pm 0.21 \mathrm{~Bq} / \mathrm{kg}$.

It is well known that rivers water, lakes are vulnerable to oil and gas related effluent discharges, gas flare and other anthropogenic activities, which may enhance the natural activity levels of the area and human exposure. As a consequence the obtained values of the activity concentration of the natural radioactive isotopes for water samples in particular ${ }^{226} \mathrm{Ra}$ deserve special interest to establish the necessary precautions to overcome that complexity. 
Table 1. Activity concentrations ( $\left.\mathrm{Bq} / \mathrm{kg}^{-}\right)$of the measured radionuclides in the samples collected from upstream plant (USP) and pipelines of natural gas grid (NG).

\begin{tabular}{|c|c|c|c|c|}
\hline Code & $\mathrm{Ra}-226 \mathrm{~Bq} / \mathrm{kg}$ & $\mathrm{Th}-232 \mathrm{~Bq} / \mathrm{kg}$ & $\mathrm{Pb}-210 \mathrm{~Bq} / \mathrm{kg}$ & $\mathrm{K}-40 \mathrm{~Bq} / \mathrm{kg}$ \\
\hline USPF1 & $10.40 \pm 0.9$ & $10.50 \pm 0.9$ & $300.54 \pm 0.09$ & $98.40 \pm 5.7$ \\
\hline USPF2 & $12.88 \pm 1.2$ & $12.55 \pm 0.5$ & $250.58 \pm 0.10$ & $115.28 \pm 8.1$ \\
\hline USPF3 & $8.03 \pm 1.1$ & $8.47 \pm 1.3$ & $322.610 \pm 0.14$ & $102.70 \pm 4.3$ \\
\hline USPF4 & $16.4 \pm 1.5$ & $10.339 \pm 2.6$ & $279.06 \pm 0.23$ & $91.373 \pm 3.1$ \\
\hline USPF5 & $23.19 \pm 2.1$ & $9.151 \pm 3.1$ & $1664 \pm 0.25$ & $99.570 \pm 7.4$ \\
\hline USPF6 & $26.34 \pm 2.2$ & $11.856 \pm 1.2$ & $906.93 \pm 0.03$ & $88.177 \pm 9.2$ \\
\hline Average for filter & $16.206 \pm 1.5$ & $10.506 \pm 0.9$ & $620 \pm 0.21$ & $98.46 \pm 6.03$ \\
\hline USPSC-1 & $37.20 \pm 3.1$ & $45.33 \pm 0.5$ & $34.99 \pm 1.23$ & $621.79 \pm 5.2$ \\
\hline USPSC-2 & $38.90 \pm 2.8$ & $48.13 \pm 3.1$ & $39.13 \pm 2.44$ & $635.24 \pm 12.2$ \\
\hline USPSC-3 & $35.76 \pm 3.1$ & $43.64 \pm 4.2$ & $30.21 \pm 6.35$ & $608.35 \pm 11.3$ \\
\hline Average for scales & $37.286 \pm 3.1$ & $45.7 \pm 2.6$ & $34.77 \pm 5.63$ & $621.793 \pm 9.5$ \\
\hline NGS1 & $13.71 \pm 1.5$ & $6.89 \pm 0.75$ & $70.59 \pm 10.23$ & $133.30 \pm 9.2$ \\
\hline NGS2 & $16.33 \pm 1.3$ & $9.93 \pm 0.9$ & $73.52 \pm 9.25$ & $147.69 \pm 7.8$ \\
\hline NGS3 & $11.19 \pm 7.1$ & $3.88 \pm 0.5$ & $67.76 \pm 6.54$ & $118.98 \pm 6.4$ \\
\hline NGS4 & $13.84 \pm 1.2$ & $11.31 \pm 0.1$ & $77.76 \pm 6.45$ & $89.20 \pm 5.1$ \\
\hline NGS5 & $16.02 \pm 1.3$ & $12.43 \pm 0.98$ & $72.79 \pm 7.36$ & $91.57 \pm 0.3$ \\
\hline NGS6 & $17.04 \pm 1.5$ & $12.85 \pm 0.98$ & $80.73 \pm 4.69$ & $93.60 \pm 4.2$ \\
\hline NGS7 & $14.31 \pm 2.3$ & $11.66 \pm 10.2$ & $71.57 \pm 2.64$ & $98.31 \pm 3.6$ \\
\hline NGS8 & $11.56 \pm 1.8$ & $9.48 \pm 0.78$ & $56.06 \pm 2.87$ & $105.33 \pm 3.5$ \\
\hline NGS9 & $11.37 \pm 1.3$ & $10.21 \pm 0.96$ & $62.68 \pm 3.68$ & $81.70 \pm 3.6$ \\
\hline NGS10 & $14.78 \pm 0.8$ & $8.701 \pm 0.6$ & $39.73 \pm 3.20$ & $64.09 \pm 3.6$ \\
\hline NGS11 & $10.57 \pm 0.9$ & $8.20 \pm 0.7$ & $63.76 \pm 6.34$ & $60.43 \pm 2.9$ \\
\hline NGS12 & $19.23 \pm 1.2$ & $15.72 \pm 1.3$ & $72.46 \pm 9.45$ & $123.98 \pm 5.3$ \\
\hline NGS13 & $17.82 \pm 1.2$ & $8.95 \pm 0.75$ & $54.68 \pm 3.47$ & $163.29 \pm 11.3$ \\
\hline NGS14 & $22.20 \pm 3.5$ & $13.80 \pm 1.3$ & $86.80 \pm 4.36$ & $172.14 \pm 7.3$ \\
\hline NGS15 & $14.65 \pm 2.3$ & $5.85 \pm 0.65$ & $69.77 \pm 1.56$ & $148.72 \pm 6.6$ \\
\hline \multirow[t]{2}{*}{ Average for sludge } & $14.97 \pm 1.94$ & $9.99 \pm 1.48$ & $68.04 \pm 2.01$ & $112.82 \pm 5.82$ \\
\hline & $\mathrm{Bq} / 1$ & $\mathrm{~Bq} / 1$ & $\mathrm{~Bq} / 1$ & $\mathrm{~Bq} / \mathrm{l}$ \\
\hline USPW1 & $5.91 \pm 0.7$ & $2.93 \pm 0.4$ & $35.94 \pm 8.35$ & $32.583 \pm 0.1$ \\
\hline USPW2 & $6.96 \pm 0.9$ & $2.94 \pm 0.3$ & $46.73 \pm 6.54$ & $35.68 \pm 3.1$ \\
\hline USPW3 & $4.90 \pm 0.5$ & $2.15 \pm 0.25$ & $28.31 \pm 9.12$ & $29.48 \pm 4.3$ \\
\hline USPW4 & $5.3 \pm 0.4$ & $2.60 \pm 0.23$ & $24.87 \pm 5.78$ & $27.56 \pm 2.5$ \\
\hline USPW5 & $3.4 \pm 0.32$ & $1.6 \pm 0.35$ & $34.11 \pm 3.87$ & $35.2 \pm 3.5$ \\
\hline USPW6 & $2.9 \pm 0.26$ & $1.23 \pm 0.48$ & $27.28 \pm 3.56$ & $31.34 \pm 0.4$ \\
\hline Average for water & $4.895 \pm 0.51$ & $2.247 \pm 0.33$ & $32.87 \pm 4.51$ & $31.852 \pm 2.31$ \\
\hline
\end{tabular}

Where; USPF is the upstream filter sample, USPSC is the upstream scales sample, NGS is the national gasgrid sludge

The reason for the high values is that $\mathrm{Rn}-222$ and its daughters (Po-218, Pb-214, Bi-214 and Po-210) are short lived compared with $\mathrm{Pb}-210$. Therefore $\mathrm{Pb}-210$ deposits originating from $\mathrm{Rn}-222$ appear in high concentrations due to the prolonged processing in all types of deposits in natural gas upstream facilities.
The experimental results of absorbed dose, annual effective dose, radium equivalent and gamma index for all the investigated samples are presented in table 2 . The calculated $\mathrm{Ra}_{\mathrm{eq}}$ activities of all samples are below the recommended value $370 \mathrm{~Bq} / \mathrm{kg}$. The average values for gamma index for all the investigated samples presented in table 2 are less than unity.

Table 2. Values of absorbed dose (D), annual effective dose (AEDE), radium equivalent $\left(R a_{e q}\right)$ and gamma index (Iyr) for all investigated samples.

\begin{tabular}{lllll}
\hline Code & $\mathbf{D}(\mathbf{n G y} / \mathbf{h})$ & $\mathbf{A E D E}(\mathbf{m S v} / \mathbf{y})$ & $\mathbf{R a}_{\mathbf{e q}}(\mathbf{B q} / \mathbf{K g})$ \\
\hline USPF1 & 15.250 & 0.187 & 32.99 & 0.119 \\
USPF2 & 18.337 & 0.224 & 39.70 & 0.144 \\
USPF3 & 12.232 & 0.150 & 26.43 & 16.4 \\
USPF4 & 7.576 & 0.092 & 23.19 & 0.096 \\
USPF5 & 10.713 & 0.131 & 26.34 & 0.054 \\
USPF6 & 12.169 & 0.149 & 27.509 & 0.087 \\
average & 12.713 & 0.155 & 149.899 & 0.096 \\
USPSC-1 & 70.494 & 0.864 & 156.639 & 145.008 \\
USPSC-2 & 73.531 & 0.901 & 0.557 \\
USPSC-3 & 68.247 & 0.836 & 0.582 \\
Average & 70.758 & 0.867 & 150.515 \\
\hline
\end{tabular}




\begin{tabular}{lllll}
\hline Code & $\mathbf{D}(\mathbf{n G y} / \mathbf{h})$ & AEDE $(\mathbf{m S v} / \mathbf{y})$ & $\mathbf{R a}_{\mathbf{e q}}(\mathbf{B q} / \mathbf{K g})$ & $\mathbf{I}_{\mathbf{y r}}$ \\
\hline USPW1 & 5.858 & 0.071 & 12.608 & 0.045 \\
USPW2 & 6.479 & 0.079 & 13.911 & 0.049 \\
USPW3 & 4.791 & 0.058 & 10.244 & 0.036 \\
USPW4 & 5.168 & 0.063 & 11.140 & 0.039 \\
USPW5 & 4.005 & 0.049 & 8.398 & 0.031 \\
USPW6 & 3.389 & 0.041 & 7.072 & 0.026 \\
Average & 4.948 & 0.060 & 10.562 & 0.038 \\
NGS1 & 16.054 & 0.196 & 33.826 & 0.124 \\
NGS2 & 19.700 & 0.241 & 0.153 \\
NGS3 & 12.474 & 0.152 & 25.802 & 0.096 \\
NGS4 & 16.944 & 0.207 & 0.132 \\
NGS5 & 18.727 & 0.239 & 36.881 & 0.146 \\
NGS6 & 19.537 & 0.217 & 0.152 \\
NGS7 & 17.753 & 0.189 & 42.622 & 0.138 \\
NGS8 & 15.458 & 0.181 & 38.553 & 0.121 \\
NGS9 & 14.826 & 0.180 & 33.226 & 0.116 \\
NGS10 & 14.756 & 32.261 & 0.114 \\
NGS11 & 12.356 & 0.151 & 32.157 & 0.096 \\
NGS12 & 23.549 & 0.288 & 26.949 & 0.184 \\
NGS13 & 20.447 & 0.250 & 51.256 & 0.158 \\
NGS14 & 25.769 & 0.316 & 43.191 & 0.200 \\
NGS15 & 16.503 & 0.202 & 55.188 & 0.127 \\
Average & 17.657 & 0.216 & 34.466 & 0.137 \\
\hline
\end{tabular}

\section{Conclusion}

The present results of NORM concentrations for samples collected from the Egyptian national gas grid and upstream processing plant and the associated calculated parameters can be used to drive the following conclusions:

- Sludge samples taken from the upstream plant showed the highest radioactity concentration with an average value of $37.28,45.7$ and 621.79 for ${ }^{226} \mathrm{Ra},{ }^{232} \mathrm{Th}$ and ${ }^{40} \mathrm{~K}$ respectively.

- The value of radioactive concentration in waste water was found to be relatively high according to the safety value $(1 \mathrm{~Bq} / \mathrm{l})$ recommended for ${ }^{226} \mathrm{Ra}$ in water which was attributed to the fact that radium-226 are partially dissolved in water. This has to be considered during disposal of this water to the outer environment to avoid contamination of different waters.

- Relatively high values of ${ }^{210} \mathrm{~Pb}$ were detected in the water samples ranging from 24.78 to $46.73 \mathrm{~Bq} / \mathrm{l}$ with an average values equal to $32.78 \mathrm{~Bq} / \mathrm{l}$.

- In general, it was noticed that NORM concentrations in all the investigated samples except water samples of the Egyptian natural gas grid are below the limits recommended by IAEA.

- Although the lower levels of radioactivity concentrations of ${ }^{226} \mathrm{Ra},{ }^{232} \mathrm{Th}$ and ${ }^{40} \mathrm{~K}$ there exist corresponding high values of ${ }^{210} \mathrm{~Pb}$. Therefore, people engaged in gas industry, especially those working in maintenance and pipeline cleaning have to flow restricted work instructions and wear appropriate personal protective equipment's to avoid risk of internal contamination.

\section{References}

[1] E. Rowan, M. Angle, C. Kirby and T. Kraemer, "Radium Content of Oil- and Gas Field Produced Waters in the Northern Appalachian Basin" (USA): Summary and Discussion of Data, Scientific Investigations Report 20115135, USGS Reston, VA, United States, 2011.

[2] F. A. Hartog, W. A. I. Knaepen, and G. Jonkers, "Radioactive lead: An underestimated issue, in Proceedings of the 1995 API and GRI Naturally Occurring Radioactive Material (NORM)" Conference, pp. 59-69 (API Publication 7104) Houston, USA, October 16-18, 1995.

[3] F. A. Hartog, W. A. I. Knaepen, G. Jonkers, A. P. Schmidt, R. D. Schuiling, and P. F. J. Lancee, "Origin and Encounter of ${ }^{210} \mathrm{~Pb}$ in E\&P facilities", in Proc. 2nd International Symposium on the Treatment of Naturally Occurring Radioactive Material, Krefeld, Germany, pp.53-57, November 10-13, 1998.

[4] A. P. Schmidt, "Naturally Occurring Radioactive Materials in the Gas and Oil Industry" Thesis, Geologica Ultraiectina, Mededelingen van de Faculteit Aardwetenschappen, University of Utrecht, the Netherlands, p. 144, 2000.

[5] F. A. Hartog, G. Jonkers, A. P. Schmidt and R. D. Schuiling, "Lead Deposits in Dutch Natural Gas Systems", Society of Petroleum Engineers paper SPE68316-MS, 2001.

[6] NRPB, NORM in the Oil and Gas Industries, Radiation at Work Series NRPB, 1999.

[7] C. Organo and D. Fenton, "Radiological assessment of NORM industries in Ireland- Radiation doses to workers and members of the public", Radiological Protection Institute of Ireland, Dec. 2008. 
[8] IAEA, Radiation Protection and the Management of Radioactive Waste in the Oil and Gas Industry, Safety Series No. 34, ISBN 92-0-114003-7, 2003.

[9] IAEA, Regulatory and management approach for the control of environmental residues containing naturally occurring radioactive material (NORM), IAEA-TECDOC1484, 2004.

[10] T. strand, "Handling And Disposal Of Norm In The Oil And Gas Industry", Norway, 1999.

[11] Saudi Aramco Engineering Procedure (SAEP-0358) "Management of Technologically Enhanced Naturally Occurring Radioactive Material (NORM)”, 2005.

[12] K. P. Smith, D. L. Blunt, G. P. Williams, and C. L. Tebes,"Radiological Dose Assessment Related to Management of Naturally Occurring Radioactive Materials Generated by the Petroleum Industry" Environmental Assessment Division Argonne National Laboratory, 9700 South Cass Avenue, Argonne, 1996.

[13] S. U. El-Kameesy, S. Y. Afifi, A. Hamid, Ali Ajeeb. "Elemental and Radioactivity Concentration of Stream Sediments in Abu-Rusheid, Nugrus Area-South Eastern Desert, Egypt”, Amer. J. Phys. Appl., 3,6, 183-189, 2015.

[14] J. Beretka, and P. J. Mathaw,"Natural Radioactivity of Australian Building Material, Industrial Wastes And By Products", Health Phys., 48, 87-95, 1985.
[15] M. Al-Abyad, S. U. El-Kameesy, S. A. El-Fiki, M. N. Dahesh, "Radioactivity Levels and Dose Evaluation in Some Environmental Rock Samples From Taiz, Yemen", Global Journal of Physics, Vol. 4, No 1, 266-275, 2016.

[16] UNSCEAR, "Exposure of the Public and Workers from Various Sources of Radiation", Report to General Assembly+, With Scientific Annexes, United Nation, New York, 2008.

[17] H. SURBECK, The science of the total environment, 91, 173174, 1995.

[18] (HECS), Healthy Environments and Consumer Safety, Radiological Characteristics Guidelines, 1995.

[19] Naturally occurring radioactive Materials (NORM) in produced water and oil-field equipment- an issue for the energy industry, USGS science for a changing world, September, 1999.

[20] U. S. Environmental Protection Agency, A Preliminary Risk Assessment of Management and Disposal Options for Oil Field Wastes and Piping Contaminated with NORM in the State of Louisiana Peer Review Draft, Office of Radiation and Indoor Air, Washington, D.C,1993b.

[21] U. S. Environmental Protection Agency, Drinking Water Regulations and Health Advisories, EPA 822-R-94-001, Office of Water, Washington, D. C, 1994. 